\section{Effect of Riboflavin on the Precocious Maturation of Spine Grape Berries (Vitis davidii Foex)}

\author{
Mingtao Zhu', Jun Yu' ${ }^{1}$, Sheng Wu, Meijun Wang, and Guoshun Yang ${ }^{2}$ \\ Horticulture \& Landscape College, Hunan Agricultural University, Changsha, \\ Hunan 410128, China; and Hunan Engineering and Technology Research \\ Center for Grape, Changsha, Hunan 410128, China
}

Additional index words. antioxidant enzymes, precocious maturation, riboflavin, spine grape

\begin{abstract}
Spine grape (Vitis davidii Foex) is an important wild plant species in South China. To provide economical and environmentally safe ways to promote the precocious maturation of spine grape berries, the effects of riboflavin were investigated. Riboflavin affected the reactive oxygen species metabolism in spine grape berries by increasing superoxide radical production and the hydrogen peroxide content, and it impaired the activities of the antioxidant enzymes superoxide dismutase and catalase. Riboflavin also induced the upregulated expression of maturation-related genes in advance, and the earlier accumulation of anthocyanin and total soluble solids. Phenological observations revealed that the treated grape berries underwent a color-turning stage 9 days earlier than the control, and the maturation stage occurred 7 days earlier than the control. Thus, riboflavin may significantly promote the precocious maturation of spine grape berries.
\end{abstract}

Spine grape is a wild grape species in South China that is also called Chinese Bramble grape and Davids Rebe. It belongs to the East Asian Vitis spp. (Meng et al., 2012a) and is mainly distributed in Hunan and Jiangxi Provinces (China). It is rich in anthocyanins, used to produce table grapes, wine, and juice, and loved by local people (Liang et al., 2013; Meng et al., 2012b). However, the maturation stage of spine grape occurs late, which affects its popularization and applications. Fruit maturation is regulated by the various internal and external factors, such as genetic factors, developmental signals, hormones, light, and temperature (Klee and Giovannoni, 2011; Qin et al., 2012; Tian et al., 2013). It is important to find an environmentally friendly and cost-effective way to promote its maturation stage. The use of growth-regulating chemicals and appropriate horticultural manipulations are traditional methods of achieving this aim. Ethylene plays a crucial role in regulating climacteric fruit maturation (Alba et al., 2005), but spine grape is a nonclimacteric fruit and is not sensitive to exogenous ethylene during the ripening process (Causier et al., 2002). However, the production of

Received for publication 1 May 2019. Accepted for publication 17 June 2019.

We thank Lesley Benyon, PhD, from Liwen Bianji, Edanz Group China (www.liwenbianji.cn/ac), for editing the English text of a draft of this manuscript.

This work was supported by the National Technology System for Grape Industry (CARS-29-ZP-9) and National key research and development program (2018YFD0201300).

${ }^{1}$ These authors contributed equally.

${ }^{2}$ Corresponding author. E-mail: guoshunyang@ aliyun.com new regulatory chemicals has presented more possibilities for controlling grape maturation.

Reactive oxygen species (ROS), including superoxide radicals $\left(\mathrm{O}_{2}^{-}\right)$hydrogen peroxide $\left(\mathrm{H}_{2} \mathrm{O}_{2}\right)$, hydroxyl radicals, and singlet oxygen, play crucial roles as key regulators of growth, development, and defense pathways in plants (Bhattacharjee, 2005; Chen et al., 2012; Mittler et al., 2004). ROS participate in a number of reduction-oxidation (redox) processes, and create a localized oxidative environment that facilitates signaling (Asada, 2006). However, a high level of ROS accumulation can cause cell membrane disintegration and protein oxidation, which can further initiate or promote the aging process (Chan, 2006). High ROS contents can effectively accelerate fruit senescence (Tian et al., 2004, 2013; Wang et al., 2005). The important role of ROS in fruit senescence and fungal pathogenic ability has been recognized in peach fruit (Chan et al., 2007). ROS, particularly $\mathrm{H}_{2} \mathrm{O}_{2}$ and $\mathrm{O}_{2}^{-}$, play important roles in promoting precocious maturation in muskmelon, tomato, and peach fruit (Jimenez et al., 2002; Lacan and Baccou, 1998; Qin et al., 2009).

Riboflavin, also known as vitamin $\mathrm{B}_{2}$, is an essential cofactor for many metabolic enzymes in multiple cellular processes, such as the citric acid cycle and cellular redox, and plays important roles in regulating plant growth and development (Deng et al., 2014; Taheri and Tarighi, 2010). Riboflavin is also a well-known photo sensitizer and can generate ROS during light exposure (Deng et al., 2014). Exogenous applications of riboflavin promote plant growth and induce resistance to fungal, bacterial, and viral pathogens $(\mathrm{Li}$ et al., 2012). Exogenous riboflavin can significantly affect the antioxidant metabolite content and redox homeostasis. The activities of enzymes, such as superoxide dismutase (SOD) and catalase (CAT), and the generation of different types of ROS, such as $\mathrm{O}_{2}{ }^{-}$ and $\mathrm{H}_{2} \mathrm{O}_{2}$, changed as the level of the riboflavin treatment increased (Deng et al., 2011 , 2014). In addition to promoting ROS production, riboflavin treatment also can induce the expression of mature related genes (Liu et al., 2010). Taheri and Tarighi (2011) demonstrated that riboflavin primed the expression of the lipoxygenase ( $L O X)$ gene associated with disease resistance and maturation in plants. In riboflavin-treated plants, the upregulation of the phenylalanine ammonia lyase $(P A L)$ gene, a key gene associated with plant disease resistance and anthocyanin synthesis, was demonstrated in grapevine (Boubakri et al., 2013).

The functions of riboflavin as a resistance elicitor or a mediator of resistance signal transduction in plants have been investigated (Boubakri et al., 2013). However, the effects of exogenous riboflavin applications on the precocious maturation of fruit has not previously been reported. Thus, in this study, we examined whether riboflavin could promote the precocious maturation of spine grape.

\section{Materials and Methods}

Plant growth and treatment. Six-year-old spine grape vines were used in this study. Twelve vines were grown at the experimental base of Hunan Agricultural University (Changsha, Hunan Province, China). All spine grape vines were subjected to identical pruning and cultivation practices. At $50 \mathrm{~d}$ after full bloom (50 DAB), the berries were treated with $0.5 \mathrm{mmol} \cdot \mathrm{L}^{-1}$ riboflavin containing $0.03 \%(\mathrm{v} / \mathrm{v})$ Tween- 80 at noon on a sunny day. Control berries were treated with distilled water containing $0.03 \%(\mathrm{v} / \mathrm{v})$ Tween80 . Three clusters ( 20 berries per cluster) per treatment were randomly collected at 0,10 , $20,30,40,50$, and $60 \mathrm{~d}(50,60,70,80,90$, 100 , and $110 \mathrm{DAB}$, respectively) after treatment. The flesh and peel were separated, and the peel was flash-frozen in liquid nitrogen and stored at $-80{ }^{\circ} \mathrm{C}$ until further processing.

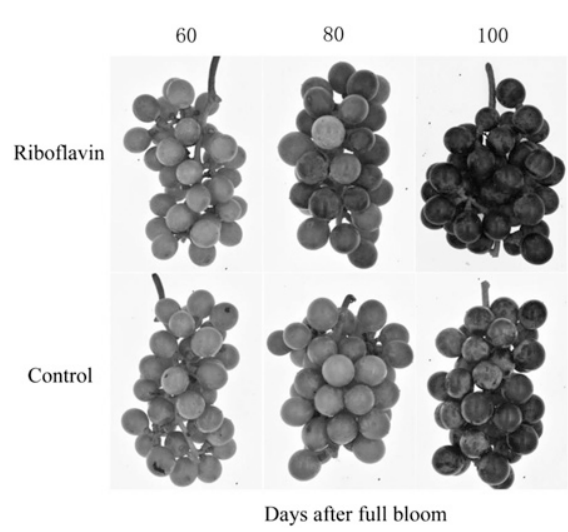

Fig. 1. Effects of riboflavin applications on spine grape berry maturation. Grape berries development stages at 60,80 , and 100 days after full bloom. 
Table 1. Effects of riboflavin on the maturation stage of spine grape berries.

\begin{tabular}{lcc}
\hline Treatment & Discoloration period (DAB) & Maturation period (DAB) \\
\hline Riboflavin & 58 & 97 \\
Control & 67 & 104 \\
\hline The discoloration period was defined as when the berries began to change from green to red; the fruit
\end{tabular}

The discoloration period was defined as when the berries began to change from green to red; the fruit maturation period was defined as when the seeds were completely brown. DAB = days after full bloom
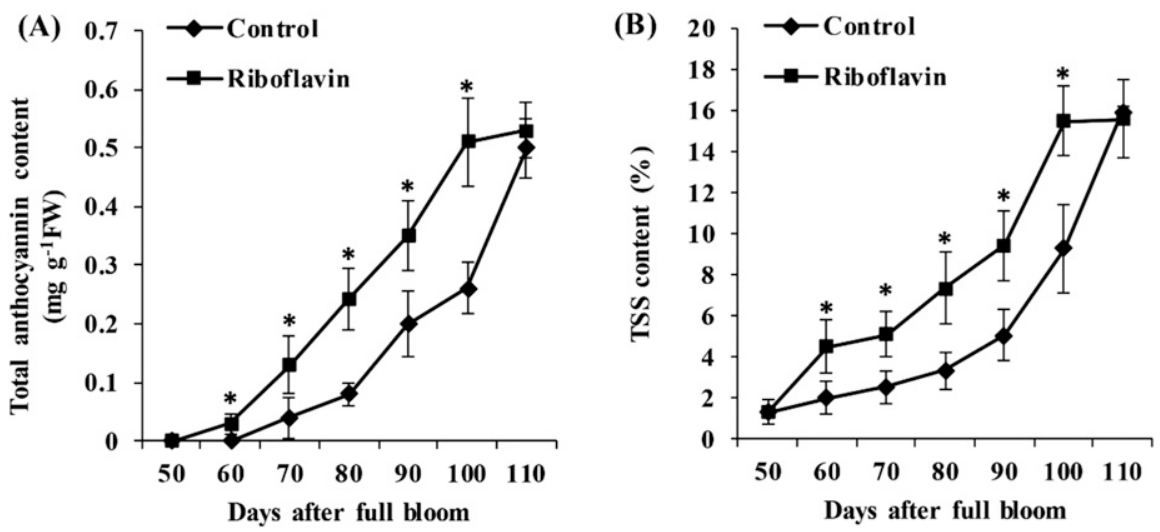

Fig. 2. Effects of riboflavin treatments on total anthocyanin (A) and total soluble solids (B) contents. Each point represents the means \pm SEs of three replicates. *Indicates significant differences at $P<0.05$ (least significant difference test). $\mathrm{FW}=$ fresh weight.

$\mathrm{H}_{2} \mathrm{O}_{2}$ and $\mathrm{O}_{2}^{-}$measurements. The accumulation of $\mathrm{H}_{2} \mathrm{O}_{2}$ and $\mathrm{O}_{2}^{-}$in spine grape peels was determined in accordance with the methods of Deng et al. (2014). The $\mathrm{H}_{2}$ $\mathrm{O}_{2}$ content was measured at $560 \mathrm{~nm}$ and expressed as nmol.g ${ }^{-1}$ fresh weight $(\mathrm{FW})$, and the $\mathrm{O}_{2}^{-}$content was measured at $530 \mathrm{~nm}$ and expressed as $\mathrm{nmol} \cdot \mathrm{min}^{-1} \cdot \mathrm{g}^{-1}$ FW.

Antioxidant enzyme activity measurements. Total protein was extracted in accordance with the methods of Zaka et al. (2002) with modifications. Briefly, fresh grape peel samples were powdered in liquid nitrogen with a precooled mortar and pestle. The needle powder $(0.5 \mathrm{~g})$ was extracted in $5 \mathrm{~mL}$ ice-cold extraction buffer (0.1-M Tris- $\mathrm{HCl} \mathrm{pH} 7.5,0.23-\mathrm{M}$ sucrose, $5 \%$ polyvinylpyrrolidone, 1-mm ethylene diamine tetraacetic acid (EDTA), 10-mM $\mathrm{KCl}, 10-\mathrm{mm} \mathrm{MgCl}_{2}$, and 2.5-mm ascorbic acid). The extract was vortexed and then placed on ice for $20 \mathrm{~min}$. Homogenized samples were then centrifuged at $14,000 \mathrm{~g}_{\mathrm{n}}$ for $15 \mathrm{~min}$ at $4{ }^{\circ} \mathrm{C}$, and the resulting supernatants were used for enzyme assays. SOD and CAT activity levels were determined in accordance with the methods of Deng et al. (2014)

Determination of anthocyanin and total soluble solids (TSS) content. The extraction of anthocyanin from grape peel was performed in accordance with the methods of Liang et al. (2011) with modifications. Briefly, fresh grape peel samples were powdered in liquid nitrogen. Then, $0.5 \mathrm{~g}$ powdered samples were placed in $1.5-\mathrm{mL}$ ice-cold extraction buffer $(2: 28: 70$, formic acid:water:methanol). The extract was vortexed for $10 \mathrm{~min}$. Then, the extracts were centrifuged at $14,000 g_{\mathrm{n}}$ for $10 \mathrm{~min}$ at $4{ }^{\circ} \mathrm{C}$, and the resulting supernatants were used for total anthocyanin assays. Total anthocyanins were determined using a $\mathrm{pH}$ differential method described by
Cheng and Breen (1991). Results were expressed as $\mathrm{mg} \cdot \mathrm{g}^{-1} \mathrm{FW}$. The TSS contents of the flesh was determined using a digital refractometer (PR-1; Atago, Tokyo, Japan) and expressed as a percentage (\%).

Expression analysis. Total RNA was extracted from spine grape peel using a TIANGEN RNA prep Pure Plant Kit (Tiangen Biotech, Beijing, China). First-strand complementary DNA (cDNA) was synthesized from $1 \mathrm{mg}$ of total RNA using a PrimeScript RT reagent kit (TaKaRa Biotechnology Co. Ltd., Dalian, China). The quantitative real-time polymerase chain reaction (PCR) amplifications were carried out in triplicate in 96-well plates, having $20 \mathrm{~mL}$ total volumes per well, using SYBR Green PCR Master Mix (TaKaRa Bio-technology Co. Ltd.) in an Applied Biosystems 7500 real-time PCR system (Applied Biosystems, Foster City, CA). The primer sequences specific for the amplification of the cDNA fragments of $P A L$ and $L O X$ are listed by Trouvelot et al. (2008). The expression levels were calculated as $2^{-\Delta \Delta \mathrm{Ct}}$ and normalized to the Ct value of VvActin (Sun et al., 2010).

\section{Results}

Effects of riboflavin applications on the maturation stage of spine grape berries. In this experiment, we took photos of spine grape clusters at 60, 80, and $100 \mathrm{DAB}$ (Fig. 1). At $60 \mathrm{DAB}$, the treated fruit had already entered the coloring period, whereas the control had not. At $80 \mathrm{DAB}$, in the riboflavin-treated clusters, the berries were mostly red, and a few were even purple, whereas in the control cluster, the berries were mostly light red and a small number of berries was still green. At $100 \mathrm{DAB}$, the treated cluster was completely purple, whereas the control was still red. As shown in Table 1, the coloring date of riboflavintreated grape berries occurred $9 \mathrm{~d}$ earlier than the control, and the fruit maturation date was $\approx 7 \mathrm{~d}$ earlier than the control.

Effects of riboflavin treatments on total anthocyanin and TSS contents. To determine whether the riboflavin treatment promoted the precocious maturation of spine grapes, total anthocyanin and TSS contents, as the main criteria for evaluating the maturity of grape fruit, were measured (Fig. 2). As is shown in Fig. 2A, the total anthocyanin contents in peels of grapes treated with riboflavin were greater than that of the control group from $60 \mathrm{DAB}$ to $100 \mathrm{DAB}$, but there were no significant differences between treatments at 110 DAB. Similarly, the riboflavin treatment of fruit promoted an early increase in the TSS contents in grape fruit, from $60 \mathrm{DAB}$ to $100 \mathrm{DAB}$, and the TSS contents of grape fruit were significantly greater than in the control.

Effects of riboflavin treatments on ROS metabolism. Based on previous knowledge regarding the role of riboflavin in peroxidation, experiments were conducted to investigate whether riboflavin is capable of generating ROS for the induction of precocious maturation in spine grapes. $\mathrm{O}_{2}^{-}$and $\mathrm{H}_{2} \mathrm{O}_{2}$, which are important ROS molecules, can be generated in plants treated with riboflavin in the light. $\mathrm{O}_{2}^{-}$production in riboflavin-treated fruit was significantly greater than in control berries, and it rapidly increased at $70 \mathrm{DAB}$ and then peaked at 80 DAB. In control berries, $\mathrm{O}_{2}^{-}$production was stable at a low level until $80 \mathrm{DAB}$, and then it increased, reaching a maximum level in samples collected at $90 \mathrm{DAB}$ (Fig. 3A). As shown in Fig. $3 \mathrm{~B}$, after the riboflavin treatment, $\mathrm{H}_{2} \mathrm{O}_{2}$ gradually increased, began to rapidly increase at $60 \mathrm{DAB}$, peaked at 80 $\mathrm{DAB}$, and then rapidly decreased. However, the $\mathrm{H}_{2} \mathrm{O}_{2}$ content of the control fruit reached its peak at $90 \mathrm{DAB}, \approx 10 \mathrm{~d}$ later than in the treated fruit.

Effects of riboflavin treatments on antioxidant enzyme activity levels. The activities of antioxidant enzymes, including SOD and CAT, were measured in spine grape berries (Fig. 4). In riboflavin-treated berries, the SOD activity remained relatively low until $70 \mathrm{DAB}$, and peaked at $80 \mathrm{DAB}$, which was earlier than the control but the peak was lower. The SOD activity was significantly lower after the riboflavin treatment from $60 \mathrm{DAB}$ to 110 DAB compared with the control berries (Fig. 4A). Similarly, riboflavin significantly restrained the CAT activity in grape berries (Fig. 4B).

Effects of riboflavin on PAL and $L O X$ gene expression levels. To understand the mechanisms involved in the riboflavininduced precocious maturation of spine grapes, the expression of $P A L$, as the starting gene of the anthocyanin biosynthetic pathway, and that of $L O X$, as the main gene associated with fruit maturation and softening, were analyzed (Fig. 5). After the riboflavin treatment, the expression patterns of 

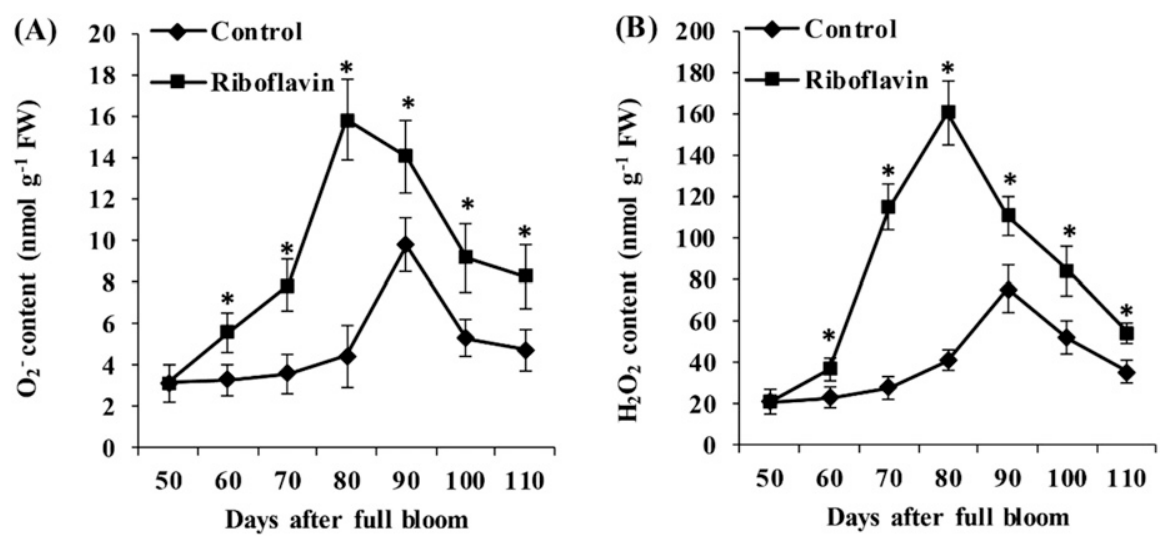

Fig. 3. Effects of riboflavin treatments on $\mathrm{O}_{2}^{-}$(A) production and the $\mathrm{H}_{2} \mathrm{O}_{2}$ (B) content. Each point represents the means \pm SEs of three replicates. *Indicates significant differences at $P<0.05$ (least significant difference test). $\mathrm{FW}=$ fresh weight.
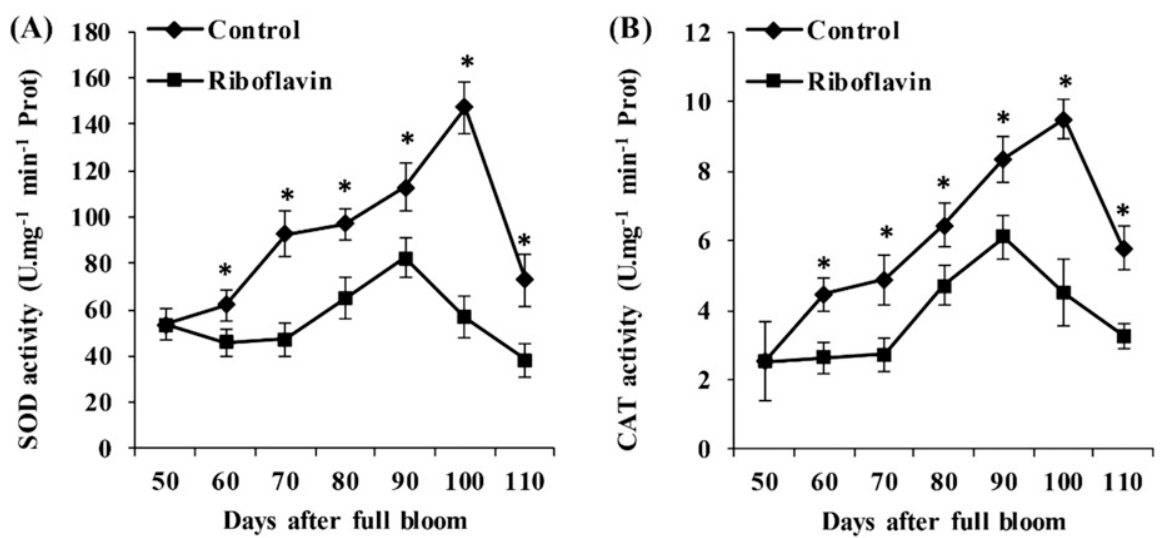

Fig. 4. Effects of riboflavin on superoxide dismutase (SOD) (A) and catalase (CAT) (B) activity levels in spine grape berry skins. Each point represents the means \pm SEs of three replicates. *Indicates significant differences at $P<0.05$ (least significant difference test). Prot $=$ protein.
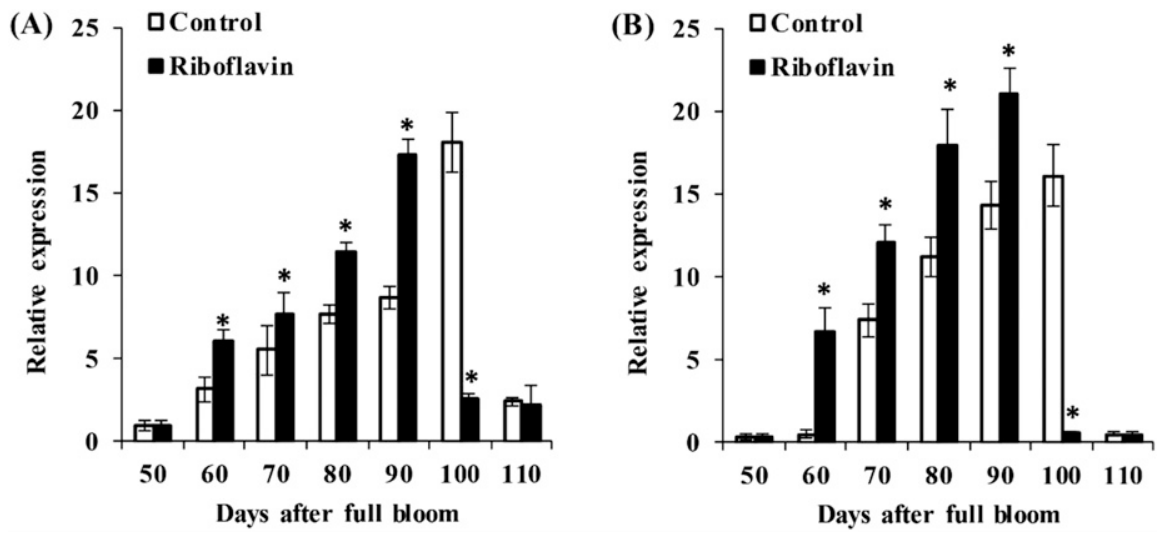

Fig. 5. Effects of riboflavin on phenylalanine ammonia lyase $(P A L)(\mathbf{A})$ and lipoxygenase $(L O X)(\mathbf{B})$ gene expression levels. Each point represents the means \pm SEs of three replicates. *Indicates significant differences at $P<0.05$ (least significant difference test).

$P A L$ (Fig. 5A) and $L O X$ (Fig. 5B) genes were similar, and there were no significant differences between the first stage before treatment and the last stage after treatment. However, from $60 \mathrm{DAB}$ to $90 \mathrm{DAB}$, both $P A L$ and $L O X$ genes showed upregulated expression levels in both treated and control berries, but the expression levels of $P A L$ and $L O X$ genes in treated berries were significantly greater than in the control. At $100 \mathrm{DAB}, P A L$ and $L O X$ genes were downregulated owing to the maturation of the treated berries. However, the expression level of $P A L$ and $L O X$ in control peaks at $100 \mathrm{DAB}$, but the peak is later and lower than the riboflavin-treated berries.

\section{Discussion}

The use of precocious maturation-related cultivation technology is of great significance because it can alter the supply period of grape fruit, which will benefit fruit farmers. To promote the precocious maturation of grape fruit, various methods have been tested, such as hormones, light, temperature, and ROS (Klee and Giovannoni, 2011; Qin et al., 2012; Tian et al., 2013). Riboflavin is a photosensitizer, which can lead to the generation of ROS, such as $\mathrm{O}_{2}^{-}$and $\mathrm{H}_{2} \mathrm{O}_{2}$ (Deng et al., 2014). In previous research, we compared the effects of different concentrations of riboflavin on the promotion of fruit maturation and found that $0.5 \mathrm{mmol} \cdot \mathrm{L}^{-1}$ of riboflavin solution had the best effect. In this study, riboflavin was applied to spine grape berries at 50 $\mathrm{DAB}$ to promote the precocious maturation of the berries. The riboflavin-treated grape berries entered the color-turning stage $9 \mathrm{~d}$ earlier than the control, and the maturation stage occurred $\approx 7 \mathrm{~d}$ earlier than in the control (Table 1, Fig. 1). Our data suggest that riboflavin-mediated ROS production affects the maturation period of spine grape berries.

Total anthocyanin and TSS accumulations are well-known signs of grape berry maturation (Koshita et al., 2011). Here, earlier and quicker rates of increase in total anthocyanin (Fig. 2A) and TSS (Fig. 2B) were observed in riboflavin-treated berries compared with the control, indicating the maturation-related priming effect of riboflavin after treatment. This finding is in agreement with early reports that the accumulation of ROS accelerated fruit senescence (Jimenez et al., 2002; Qin et al., 2009; Tian et al., 2013). In addition, when the treated and control berries were all mature at $110 \mathrm{DAB}$, there were no significant differences in anthocyanin and TSS contents, which indicated that riboflavin has little effect on anthocyanin and soluble solid contents of grape berry.

Fruit maturation is an oxidative phenomenon accompanied by a pronounced increase in ROS, particularly $\mathrm{O}_{2}^{-}$and $\mathrm{H}_{2} \mathrm{O}_{2}$, accumulation (Tian et al., 2013; Warm and Laties, 1982). Riboflavin is involved in peroxidation, which affects the production of ROS. Taheri and Tarighi (2011) reported that the oxidative burst was induced in sugar beet after they were treated with riboflavin. Li et al. (2012) also found a similar result in experiments conducted on pear fruit. $\mathrm{H}_{2} \mathrm{O}_{2}$ and $\mathrm{O}_{2}^{-}$, as important ROS, which are induced by riboflavin treatment obviously, so only these two ROS were detected in our study. Here, riboflavin treatments resulted in earlier peak values of $\mathrm{O}_{2}^{-}$(Fig. 2A) and $\mathrm{H}_{2} \mathrm{O}_{2}$ (Fig. 2B) in berries and increased their contents compared with the control. These results corroborated that $\mathrm{O}_{2}^{-}$and $\mathrm{H}_{2} \mathrm{O}_{2}$ are important forms of ROS and essential to the induction of fruit maturation (Tian et al., 2013).

To further investigate the role of riboflavin in promoting grape berry maturation, the activities of SOD, a key enzyme that dismutates $\mathrm{O}_{2}^{-}$into $\mathrm{H}_{2} \mathrm{O}_{2}$, and CAT, a key enzyme that degrades $\mathrm{H}_{2} \mathrm{O}_{2}$ into water and 
oxygen (Boubakri et al., 2013), were measured in riboflavin-treated grape berry peels. Riboflavin impaired SOD (Fig. 3A) and CAT activity levels (Fig. 3B). Similarly, Deng et al. (2014) found that riboflavin impaired antioxidant enzyme activities, which may be related to high content of ROS produced by the degradation of riboflavin.

$P A L$ is the starting gene of anthocyanin synthetic pathway, and its expression level is closely related to anthocyanin accumulation. Enhancing the expression of PAL can promote the synthesis of anthocyanins (Qzeki et al., 2010; Wang et al., 2005). Taheri and Tarighi (2010) reported that riboflavin strongly elicited the expression of $P A L$ and $L O X$ genes in rice, and they found a similar pattern in sugar beet (2011). Here, we found that riboflavin could promote the accumulation of anthocyanin in the treated berries earlier than in the control group (Fig. 1A). Moreover, during the $60-90 \mathrm{DAB}$ period, the $P A L$ gene expression (Fig. 5A) and the total anthocyanin content (Fig. 2A) in the treated fruit were greater than those in the control group. $P A L$ gene expression increases at the early ripening stages in fruit, but diminishes at the end of ripening (Pombo et al., 2011). At $100 \mathrm{DAB}$, the treated fruit were fully mature, total anthocyanin accumulation was completed, and $P A L$ gene expression was downregulated. However, the control group was not fully mature yet; therefore, the $P A L$ gene was upregulated (Fig. 5A) and the total anthocyanin accumulation was still occurring (Fig. 2A). Thus, the expression level of the $P A L$ gene in fruit treated at this point was lower than that of the control group, but the total anthocyanin content was greater than that of the control group.

$L O X$ plays an important role in plant growth, development, and maturation, as well as resistance to mechanical damage, disease, and insect infection (Heitz et al., 1997; Marcelle, 1991). In higher plants, $L O X$ is associated with the synthesis of ethylene, jasmonic acid, and abscisic acid, which contribute to fruit ripening (Parry, 1991). We found similar results (Fig. 5B). Before ripening, the expression of the $L O X$ gene in riboflavin-treated fruit was greater than that of the control. In line with the $P A L$ gene expression pattern, the expression level of the $L O X$ gene decreased in the later stages of fruit ripening (Lin et al., 2018). Consequently, we found that the expression of the $L O X$ gene in treated fruit was lower than that in the control at $100 \mathrm{DAB}$.

\section{Conclusion}

In conclusion, our study showed the ability of riboflavin to promote the precocious maturation of spine grape. Riboflavin induces maturation responses, including $\mathrm{O}_{2}^{-}$and $\mathrm{H}_{2} \mathrm{O}_{2}$ accumulation, decreased antioxidant enzyme activity, the upregulated expression of maturation-related genes in advance, and the earlier accumulation of anthocyanin and TSS. We also showed the effects of riboflavin treatments on the col- oring and maturation stages of grapes. Our results suggest that riboflavin could be used to promote the maturation stage of spine grape under field conditions. The safety of riboflavin applications and their efficient promotion of maturation could be useful in developing new, simple, and environmentally safe vineyard management strategies.

\section{Literature Cited}

Alba, R., P. Payton, Z. Fei, R. Mcquinn, P. Debbie, G.B. Martin, S.d. Tanksley, and J.J. Giovannoni. 2005. Transcriptome and selected metabolite analyses reveal multiple points of ethylene control during tomato fruit development. Plant Cell 17:2954-2965.

Asada, K. 2006. Production and scavenging of reactive oxygen species in chloroplasts and their functions. Plant Physiol. 141:391-396.

Bhattacharjee, S. 2005. Reactive oxygen species and oxidative burst: Roles in stress, senescence and signal transduction in plant. Curr. Sci. 89:1113-1121.

Boubakri, H., J. Chong, A. Poutaraud, C. Schmitt, C. Bertsch, A. Mliki, J.E. Masson, and I. Soustre-Gacougnolle. 2013. Riboflavin (Vita$\min \mathrm{B}_{2}$ ) induces defence responses and resistance to Plasmopara viticola in grapevine. Eur. J. Plant Pathol. 136:837-855.

Causier, B., M. Kieffer, and B. Davies. 2002. MADS-box genes reach maturity. Science 296:275-276.

Chan, D.C. 2006. Mitochondria: Dynamic organelles in disease, ageing, and development. Cell 125:1241-1252.

Chan, Z.L., G.Z. Qin, X.B. Xu, B.Q. Li, and S.P. Tian. 2007. Proteome approach to characterize proteins induced by antagonist yeast and salicylic acid in peach fruit. J. Proteome Res. 6:1677-1688.

Chen, G.H., C.P. Liu, S.C.G. Chen, and L.C. Wang. 2012. Role of ARABIDOPSIS A-FIFTEEN in regulating leaf senescence involves response to reactive oxygen species and is dependent on ETHYLENE INSENSITIVE2. J. Expt. Bot. 63:275-292.

Cheng, G.W. and P.J. Breen. 1991. Activity of phenylalanine ammonia-lyase (PAL) and concentrations of anthocyanins and phenolics in developing strawberry fruit. J. Amer. Soc. Hort. Sci. 16:865-869.

Deng, B.L., S. Deng, F. Sun, S.J. Zhang, and H.S. Dong. 2011. Down-regulation of free riboflavin content induces hydrogen peroxide and a pathogen defense in Arabidopsis. Plant Mol. Biol. 77:185-201.

Deng, B.L., X.H. Jin, Y. Yang, Z.W. Lin, and Y.L. Zhang. 2014. The regulatory role of riboflavin in the drought tolerance of tobacco plants depends on ROS production. Plant Growth Regulat. 72:269-277.

Heitz, T., D.R. Bergey, and C.A. Ryan. 1997. A gene encoding a chloroplast-targeted lipoxygenase in tomato leaves is transiently induced by wounding, systemin, and methyl jasmonate. Plant Physiol. 114:1085-1093.

Jimenez, A., G. Creissen, B. Kular, J. Firmin, S. Robinson, M. Verhoeyen, and P. Mullineaux. 2002. Changes in oxidative processes and components of the antioxidant system during tomato fruit ripening. Planta 214:751-758.

Klee, H.J. and J.J. Giovannoni. 2011. Genetics and control of tomato fruit ripening and quality attributes. Annu. Rev. Genet. 45:41-59.

Koshita, Y., T. Yamane, H. Yakushiji, A. Azuma, and N. Mitani. 2011. Regulation of skin color in 'aki queen' grapes: Interactive effects of tem- perature, girdling, and leaf shading treatments on coloration and total soluble solids. Scientia Hort. 129:98-101.

Lacan, D. and J.C. Baccou. 1998. High levels of antioxidant enzymes correlate with delayed senescence in nonnetted muskmelon fruits. Planta 204:377-382.

Li, Y., Y. Yin, Y. Bi, and D. Wang. 2012. Effect of riboflavin on postharvest disease of Asia pear and the possible mechanisms involved. Phytoparasitica 40:261-268.

Liang, N., Q. Pan, F. He, J. Wang, M.J. Reeves, and C. Duan. 2013. Phenolic Profiles of Vitis davidii and Vitis quinquangularis species native to China. J. Agr. Food Chem. 61:60166027.

Liang, Z.C., C.L. Owens, G.Y. Zhong, and L.L. Cheng. 2011. Polyphenolic profiles detected in the ripe berries of Vitis vinifera germplasm. Food Chem. 129:940-950.

Lin, H., S.S. Wang, T. Saito, K. Ohkawa, H. Ohara, A. Kongsuwan, H.F. Jia, Y.S. Guo, H. Tomiyama, and S. Kondo. 2018. Effects of IPT or NDGA application on ABA metabolism and maturation in grape berries. J. Plant Growth Regul. 37:1210-1221.

Liu, F., W. Fang, L. Wang, H. Liu, X. Zhu, and L. Yuancun. 2010. Riboflavin activates defense responses in tobacco and induces resistance against Phytophthora parasitica and Ralstonia solanacearum. Physiol. Mol. Plant Pathol. 74:330-336.

Marcelle, R.D. 1991. Relationships between mineral content, lipoxygenase activity, levels of 1-aminocyclopropane-1-carboxylic acid and ethylene emission in apple fruit flesh disks (cv. Jonagold) during storage. Postharvest Biol. Technol. 1:101-109.

Meng, J.F., Y.L. Fang, J.S. Gao, L.L. Qiao, A. Zhang, Z.J. Guo, M.Y. Qin, J.Z. Huang, Y. Hu, and X.F. Zhang. 2012b. Phenolics composition and antioxidant activity of wine produced from spine grape (Vitis davidii Foex) and cherokee rose (Rosa laevigata Michx.) fruits from south China. J. Food Sci. 77:C8C14.

Meng, J.F., Y.L. Fang, M.Y. Qin, X.F. Zhuang, and Z.W. Zhang. 2012a. Varietal differences among the phenolic profiles and antioxidant properties of four cultivars of spine grape (Vitis davidii Foex) in Chongyi County (China). Food Chem. 134:2049-2056.

Mittler, R., S. Vanderauwera, M. Gollery, and B.F. Van. 2004. Reactive oxygen gene network of plants. Trends Plant Sci. 9:490-498.

Parry, A.D. 1991. Carotenoid metabolism and the biosynthesis of abscisic acid. Phytochemistry 30:815-821.

Pombo, M.A., G.A. Martínez, and P.M. Civello. 2011. Cloning of FaPAL6 gene from strawberry fruit and characterization of its expression and enzymatic activity in two cultivars with different anthocyanin accumulation. Plant Sci. 181:111-118.

Qin, G., Y. Wang, B. Cao, W. Wang, and S. Tian. 2012. Unraveling the regulatory network of the MADS box transcription factor RIN in fruit ripening. Plant J. 70:243-255.

Qin, G.Z., Q. Wang, L. Jia, B.Q. Li, and S.P. Tian. 2009. Proteomic analysis of changes in mitochondrial protein expression during fruit senescence. Proteomics 9:4241-4253.

Qzeki, Y., K. Matsui, M.A. Sakuta, M. Matsuoka, Y. Ohashi, and Y. Kano-Murakami. 2010. Differential regulation of phenylalanine ammonialyase genes during anthocyanin synthesis and by transfer effect in carrot cell suspension cultures. Physiol. Plant. 80:379-387. 
Sun, L., M. Zhang, J. Ren, J.X. Qi, G.J. Zhang, and P. Leng. 2010. Reciprocity between abscisic acid and ethylene at the onset of berry ripening and after harvest. BMC Plant Biol. 10:257268.

Taheri, P. and S. Tarighi. 2011. A survey on basal resistance and riboflavin-induced defense responses of sugar beet against Rhizoctonia solani. J. Plant Physiol. 168:1114-1122.

Taheri, S. and S. Tarighi. 2010. Riboflavin induces resistance in rice against Rhizoctonia solani via jasmonate-mediated priming of phenylpropanoid pathway. J. Plant Physiol. 167:201-208.

Tian, S., G. Qin, and B. Li. 2013. Reactive oxygen species involved in regulating fruit senescence and fungal pathogenicity. Plant Mol. Biol. 82:593-602.

Tian, S.P., A.L. Jiang, Y. Xu, and Y.S. Wang. 2004. Responses of physiology and quality of sweet cherry fruit to different atmospheres in storage. Food Chem. 87:43-49.

Trouvelot, S., A.L. Varnier, M. Allègre, L. Mercier, F. Baillieul, C. Arnould, V. Gianinazzi-Pearson, O. Klarzynski, J.M. Joubert, A. Joubert, and X. Daire. 2008. A beta-1,3 glucan sulfate induces resistance in grapevine against plasmopara viticola through priming of defense responses, including HR-like cell death. Mol. Plant Microbe Interact. 21:232-243.
Wang, Y.S., S.P. Tian, and Y. Xu. 2005. Effects of high oxygen concentration on pro- and anti-oxidant enzymes in peach fruits during postharvest stages. Food Chem. 91:99-104.

Warm, E. and G.G. Laties. 1982. Quantification of hydrogen peroxide in plant extracts by the chemiluminescence reaction with luminol. Phytochemistry 1:7-31.

Zaka, R., C. Vandecasteele, and M. Misset. 2002. Effects of low chronic doses of ionizing radiation on antioxidant enzymes and G6PDH activities in Stipa capillata (Poaceae). J. Expt. Bot. 53:1979-1987. 